\title{
Improving the Routine Management of Rheumatoid Arthritis: The Value of Tight Control
}

\author{
PHILIP J. MEASE
}

\begin{abstract}
Evidence is mounting that adopting a tight control approach to the management of patients with rheumatoid arthritis (RA) yields superior clinical outcomes including inhibition of progressive structural damage. While this approach has been successfully implemented in other chronic diseases, such as diabetes, its use in RA is less straightforward as there is not a simple "gold standard" measure for disease activity. A key component of the tight control approach is the availability of easily implemented and clinically relevant assessment measures of disease activity that allow physicians to monitor progress toward preset goals. This article summarizes the evidence from clinical trials demonstrating the benefits of achieving tight control and surveys the instruments available to assess patient progress in a consistent manner. A case study clearly demonstrates the benefits of the tight control approach in routine clinical practice. (First Release July 1 2010; J Rheumatol 2010;37:1570-8; doi:10.3899/jrheum.091064)
\end{abstract}

Key Indexing Terms:

DISEASE MANAGEMENT BIOLOGIC THERAPY PATIENT OUTCOMES ASSESSMENT

Rheumatoid arthritis (RA) is a chronic and generally progressive systemic autoimmune disease that affects $0.5 \%-1 \%$ of adults worldwide, being more prevalent in women than in men, and in older people ${ }^{1}$. RA is characterized by chronic inflammation of the synovial membrane of affected joints. Most patients also experience deterioration of cartilage and bone over time, leading to pain, disability, and premature mortality ${ }^{1}$. Despite considerable therapeutic advances, many patients with RA experience active disease, progressive joint damage and disability, and comorbidities, including premature cardiovascular disease. No substantial improvement in survival rates has been observed over the last 40 years $^{2}$, although this situation may have begun to improve over the last decade, possibly due to changes in clinical practice and the availability of the newer biologic therapies $^{3}$. Among possible reasons for the relative lack of progress with regard to survival rates may be the infrequent use, in routine clinical practice, of suitable measures of disease control that can be used to set treatment goals and to monitor patients' progress. While numerous research tools - such as the American College of Rheumatology (ACR)

From Seattle Rheumatology Associates, Seattle, Washington, USA. Support for third-party writing assistance for this report, furnished by Neil Anderson, was provided by Genentech, Inc. and Biogen Idec.

P.J. Mease, $M D$.

Address correspondence to Dr. P.J. Mease, Seattle Rheumatology Associates, 1101 Madison Street, Suite 1000, Seattle, WA 98104, USA.

E-mail:pmease@nwlink.com

Full Release Article. For details see Reprints/Permissions at jrheum.org

Accepted for publication March 8, 2010. core data set and the Disease Activity Score (DAS) - are used in clinical trials, these complex instruments are unsuitable for busy rheumatology clinics. Consequently, treatment is generally determined on an individual patient basis without reference to appropriate targets, a process that has been likened to "giving treatment for a fever without a temperature, or rapid heart rate without a pulse" 4 .

Recent improvements in the treatment of RA have meant that clinical remission is now a realistic target for many patients. Indeed, it is now widely accepted that setting remission as the goal of treatment is critical in order to prevent progressive joint damage. As a result of these developments, it is now essential that clinicians have an accurate, reliable definition of remission and are able to accurately measure low levels of disease activity.

The concept of "tight control" - treating patients to specified targets with aggressive therapy if necessary - has produced important benefits in conditions such as type I diabetes mellitus ${ }^{5}$. For example, the Diabetes Control and Complications Trial showed that intensive treatment significantly reduced the risk of retinopathy progression and clinical neuropathy, and significantly lowered the risk of cardiovascular events versus standard treatment ${ }^{6}$.

In routine clinical practice, achieving tight control has 2 prerequisites. First, a validated quantitative assessment is needed to facilitate continual monitoring of disease activity over time. Second, assessments need to be quick and easy to perform in routine clinical practice, and adaptable to multiple formats. Notably, tight-control studies in patients with diabetes or hypertension have shown that improved out-

Personal non-commercial use only. The Journal of Rheumatology Copyright @ 2010 . All rights reserved. 
comes can be achieved in well informed patients who understand the meaning of the parameters being investigated ${ }^{7,8}$.

This article examines recent clinical data demonstrating the potential benefits of tight control for patients with RA, and reviews some assessment tools that may be suitable for implementing tight control. Finally, a case study illustrating the difference tight control can make to individuals with RA is presented.

\section{Advantages of Tight Control: Evidence from Clinical Trials}

Several clinical trials have demonstrated the advantages of tight control in patients with RA. Among the first was the Finnish Rheumatoid Arthritis Combination Therapy trial, which compared disease-modifying antirheumatic drug (DMARD) combination therapy against DMARD monotherapy in patients with early RA. This study was one of the first to test whether the use of early aggressive combination DMARD therapy could alter the course of the disease by inducing long-lasting remission. Treatment aimed to achieve or maintain clinical remission ${ }^{9}$, defined as meeting American College of Rheumatology (ACR) remission criteria $^{10}$. In the combination group, patients received sulfasalazine (SSZ), methotrexate (MTX), hydroxychloroquine, and prednisolone. Treatment was intensified by increasing the doses of MTX and prednisolone at 3 months if improvement in 2 of the 3 measures [swollen joint score; tender joint score; and erythrocyte sedimentation rate (ESR) or C-reactive protein (CRP)] was $<50 \%$. In the monotherapy arm, patients initially received SSZ, the dose of which was increased if clinically indicated. However, if there was $<25 \%$ clinical improvement at 6 months, SSZ was replaced with MTX. After 2 years, $37 \%$ of combination therapy patients and $18 \%$ of monotherapy patients had clinical remission, as defined by Pinals and colleagues ${ }^{11}$. Mean improvements in swollen joint count and ESR were also higher in patients receiving combination therapy than in those receiving monotherapy, although levels of disease activity as assessed by various clinical measures were similar in the 2 groups. Five-year followup results showed a drop in clinical remission rates for combination therapy, with $28 \%$ of patients achieving remission (22\% for monotherapy), although longterm retardation of joint damage continued ${ }^{12}$. Overall, this trial showed that early aggressive initial combination therapy using standard DMARD, in the context of tight disease control, can lead to high clinical remission rates and prevention of longterm joint damage.

The multicenter randomized BeSt (Behandel-Strategieën; "treatment strategies") study assessed a number of different treatment strategies in 508 patients with early $\mathrm{RA}^{13}$. The significance of this study, however, lies with the intensive monitoring specified in the protocol; patients were allocated to 1 of 4 treatment arms, with treatment being adjusted every 3 months to maintain a prespecified level of disease activity (DAS $\leq 2.4)$. For all groups, the protocol described a number of treatment steps for patients whose medications failed. Group 1 (sequential monotherapy) received MTX, the dose of which was increased if DAS was $>$ 2.4. Subsequent options included SSZ or leflunomide monotherapy. Group 2 (step-up combination therapy) also started with MTX. If response was inadequate after a dose increase, SSZ was added, followed by hydroxychloroquine, and then prednisone. Patients whose disease failed to respond could be switched to other combinations including MTX with infliximab. Group 3 (initial combination therapy with prednisone) received MTX, SSZ, and prednisone; other agents were added if response was inadequate. Group 4 (initial combination with infliximab) started with MTX and infliximab; the dose of infliximab was increased if disease failed to respond adequately. If patients still had a DAS > 2.4 despite receiving infliximab at a dose of $10 \mathrm{mg} / \mathrm{kg}$ every 8 weeks plus MTX, patients were switched to alternative treatment options. Ongoing results show that these currently available therapies can be highly effective in patients with early RA, when applied in the setting of tight disease control ${ }^{13,14,15}$. Notably, although combination therapies initially provided earlier clinical improvement and less joint damage progression, all 4 treatment strategies ultimately achieved similar clinical improvements at 2 years ${ }^{16}$. The authors also observed that combination therapy required fewer treatment adjustments compared with initial monotherapy, and could be withdrawn successfully. A subsequent study compared outcomes in patients from the BeSt study who were treated to achieve a specified disease activity target (DAS $\leq 2.4$ ) with those managed with routine care in early arthritis clinics ${ }^{16}$. At baseline, patients from the BeSt study had more advanced disease than those managed with routine care, including longer median disease duration ( 0.5 vs 0.4 yrs, respectively; $p=0.016$ ), higher mean baseline DAS28 (6.1 vs 5.6; p < 0.001), more rheumatoid factor (RF)-positive patients (66\% vs $42 \%$; $p<0.001)$, and more patients with radiographic joint damage $(71 \%$ vs $53 \%$; $\mathrm{p}<$ $0.001)$. Despite having more advanced disease, BeSt patients treated to achieve the target disease activity experienced greater improvements in functional ability scores (+0.7 vs +0.5 points, respectively; $\mathrm{p}=0.029)$, and a higher remission rate (DAS28<2.6, $31 \%$ vs $18 \%$; $p<0.005$ ) compared with routine care in early RA clinics. Overall, the results from the BeSt study illustrate how intensive monitoring of patients involving treatment to a predefined target (in this case DAS remission) is beneficial to patients with early RA. The study shows that initial treatment should be aggressive, with early use of biologic therapy considered, and that treatments should be altered quickly (either by dose escalation or switching to alternative effective agents) if the patient is not achieving the desired low level of disease activity.

The TICORA (Tight Control of Rheumatoid Arthritis) Personal non-commercial use only. The Journal of Rheumatology Copyright @ 2010 . All rights reserved. 
study compared an intensive management strategy with routine care in 111 patients with active $\mathrm{RA}^{17}$. Intensively managed patients saw a rheumatologist every month and those who had not achieved a DAS $\leq 2.4$ received a dose increase or were switched to an alternative therapy. The study began in 1999, before the introduction of biologic therapies. All patients in the intensively managed group initially received SSZ, the dose of which was increased if DAS $\leq 2.4$ was not achieved. If responses remained insufficient, further treatment options included the addition of MTX, folic acid, and hydroxychloroquine. Patients in the routine care group saw a rheumatologist every 3 months and were treated at the physician's discretion. During this 18-month study, the mean improvement in DAS was significantly greater in the intensive management group than in the routine care group $(-3.5$ vs -1.9 , respectively; $\mathrm{p}<0.0001)$. Further, more patients in the intensive management group had a good response (decrease in DAS $\geq 1.2,82 \%$ vs $44 \%$; $p<0.0001$ ) or were in remission (DAS $<1.6,65 \%$ vs $16 \%$; p $<0.0001$ ) than patients receiving routine care. Although conducted before the biologic therapies became a treatment option, the TICORA study clearly illustrates the principle that intensive management of patients using a predefined disease activity target is superior to management that does not involve a routine assessment of disease activity.

Results of the open-label CAMERA (Computer Assisted Management in Early Rheumatoid Arthritis) trial also support the contention that tight control is superior to conventional management in RA. In that study, intensive treatment with MTX was compared with conventional MTX treatment in patients with early $\mathrm{RA}^{18}$. Patients in the intensive treatment group attended the outpatient clinic every month and their MTX dose was adjusted on the basis of predefined response criteria [swollen joint count, tender joint count, ESR, and visual analog scale (VAS) assessments of general well-being and pain] using a computerized decision program. Patients in the conventional treatment group attended clinic every 3 months and were treated according to standard practice. In the intensive treatment group, $50 \%$ of patients achieved at least one period of remission during the 2-year trial compared with $37 \%$ of those receiving conventional treatment $(\mathrm{p}=0.03)$. Efficacy was significantly greater in the intensive group for almost all clinical variables, including morning stiffness $(\mathrm{p}=0.009)$, ESR $(\mathrm{p}=$ 0.007 ), tender joint count ( $\mathrm{p}<0.001)$, swollen joint count ( $\mathrm{p}<0.001)$, VAS general well-being $(\mathrm{p}<0.001)$, and VAS pain $(\mathrm{p}=0.001)$.

Results of a recent study illustrate how intensive management of early RA can lead to very high rates of clinical remission $^{19}$. In this pilot study, 21 patients with early RA were treated with an intensified COBRA regimen (SSZ, MTX, and high-dose step-down prednisolone, intensified by adding hydroxychloroquine and continued low-dose prednisolone) with the option to further intensify MTX treatment after 8 or 21 weeks and to add infliximab therapy after 21 weeks ${ }^{19}$. After 40 weeks of treatment, an impressive 19/21 patients $(90 \%)$ had achieved remission (DAS28 < 2.6).

Other recent data suggest that tight control may improve longterm functional disability ${ }^{20}$ and reduce the need for joint surgery among patients with RA treated with an anti-tumor necrosis factor (TNF) agent ${ }^{21}$. Tanaka and coworkers $^{20}$ followed 2775 patients in an observational cohort study for whom 3 years of data were available. A significant correlation was found between tight disease control (DAS28 < 2.6) and functional disability score [using the Japanese version of the Health Assessment Questionnaire (HAQ)]; tight control was significantly associated with improving functional capability. A second study in patients receiving anti-TNF treatment for $\geq 1$ year found that mean DAS28 (including a measure of CRP levels) among patients who did not require joint surgery $(n=70)$ was significantly lower $(\mathrm{p}<0.001)$ than among patients who required joint surgery $(n=21)^{21}$. The authors concluded that tight disease control was important in reducing the need for joint surgery among patients receiving biologic therapy.

Together, the data discussed above support the hypothesis that tight disease control using a specified level of disease activity as a clinical target may improve outcomes for patients with RA. One caveat is that the majority of these studies assessed the use of nonbiologic therapies. The use of biologics is widespread in the treatment of RA, and is occurring earlier in the treatment process. Further studies would therefore be valuable to assess whether the same benefits are apparent if a tight control strategy is applied to treatment with biologics. Nonetheless, these results suggest that treating patients to specified targets improves clinical outcomes, regardless of the treatment. It may be that the specific treatment administered is less important than the principle of an intensive management strategy that includes regular monitoring of disease activity and adjustment of treatments as needed. In order to integrate a tight control approach into routine rheumatology practice, it is critical that there are suitable validated assessments of disease activity, and relevant and realistic clinical targets.

\section{Assessments for Standard Clinical Care}

Measuring disease activity and remission. Although recent advances in treatment have led to an increase in the proportion of patients reaching a state of remission ${ }^{22}$ there is no "gold standard" measurement of disease activity and remission in $\mathrm{RA}^{4}$. Numerous pooled indices have been developed to measure disease activity, each of which incorporates 3-10 different assessments $23,24,25,26,27,28,29,30,31$. This in turn means that several definitions of remission, all using different criteria, have been developed. No one disease activity index is consistently used, meaning that clinical trials throughout the world assess remission using different definitions. The ACR core data set ${ }^{25,27}$ and the DAS $23,30,32$ are Personal non-commercial use only. The Journal of Rheumatology Copyright @ 2010 . All rights reserved. 
the most commonly used indices in clinical trials. The DAS assesses tender joint count, swollen joint count, ESR (or CRP, although this is less well validated than $\mathrm{ESR}^{24}$ ), and the patient's VAS estimate of general health; using a mathematical formula, the DAS score is calculated ${ }^{33}$. The ACR core data set uses the same basic assessments as the DAS (tender joint count, swollen joint count, and measurement of ESR) plus physician's and patient's assessments of global disease activity and patient evaluations of pain and physical function $^{25}$. In addition, the ACR core data set measures change in disease activity, whereas the DAS measures current disease state or severity. The DAS is generally considered to have greater utility than the ACR core data set as it can be used to determine whether a patient has achieved low disease activity or remission. DAS28, a modification of the DAS involving only a simple joint count, has also been developed and is often used. Different definitions of remission in RA exist for each index; it is defined by DAS as a score $<1.6^{34}$, by DAS28 as a score $<2.6^{23}$, and by ACR as meeting a minimum of $5 \mathrm{ACR}$ remission criteria for at least 2 consecutive months ${ }^{10}$.

Another major set of DAS-based response criteria were developed by the European League Against Rheumatism (EULAR). These criteria combine an assessment of the change in disease activity from baseline with an analysis of the DAS reached at followup; patients are classed as having a good response, a moderate response, or no response ${ }^{34}$. EULAR remission is often described as a Disease Activity Score of $<1.6^{35}$.

Simpler instruments have been developed from the complex assessment tools discussed above. Two DAS-based instruments, the Simplified Disease Activity Index (SDAI) and the Clinical Disease Activity Index (CDAI) (Tables 1 and 2$)^{24,36}$ use a simplified system of grading joint swelling and tenderness (28-joint count); further, the CDAI includes no laboratory assessments (the SDAI measures CRP). Cutoff points for SDAI and CDAI remission are defined as $\leq 3.3$ and $\leq 2.8$, respectively ${ }^{24}$. Initial validation of the SDAI showed good correlation with the DAS28 (Table 1) in both absolute scores and changes over time ${ }^{37}$. Correlation between the CDAI and SDAI was found to be almost complete, and the CDAI appeared to correlate strongly with the DAS28 ${ }^{24}$. However, results of 2 recent studies suggest that the classification of a patient as being in remission or not depends on the instrument used to define remission ${ }^{38,39}$. The studies assessed and categorized patients according to various disease activity indices, and demonstrated that a greater proportion of patients were assessed to be in remission using DAS28 disease activity criteria compared with using the CDAI and SDAI. These results suggest that the CDAI and SDAI may be more stringent assessment tools for classification of remission.

Patient questionnaires. Although patient questionnaires do not provide an objective assessment of disease activity, they do allow a global overview of patient functioning. Since 1980, the disease-specific HAQ has been used to assess functioning and global disease status in patients with $\mathrm{RA}^{40}$. The main advantage of the HAQ is that it can be completed by the patient in 5-10 minutes. Its main limitations are a somewhat complex scoring calculation and the need to use a ruler to measure VAS scores ${ }^{4}$.

To make the HAQ easier to use in standard rheumatology care, the multidimensional HAQ (MDHAQ) has been developed $^{41}$. The MDHAQ employs fewer questions than the HAQ; in addition, the VAS has been converted from a $10-\mathrm{cm}$ line to 21 circles, making it easier to evaluate (Figure

Table 1. Elements of the Simplified Disease Activity Index (SDAI), the Clinical Disease Activity Index (CDAI), the Disease Activity Score (DAS), and the 28-joint DAS (DAS28)*24.

\begin{tabular}{|c|c|c|c|c|}
\hline No. of swollen joints & Simple count $(0-28)$ & Simple count $(0-28)$ & $\begin{array}{l}\text { More extensive joint } \\
\text { counts }(0-2.86)\end{array}$ & $\begin{array}{c}\text { Simple count, square } \\
\text { root transformed }(0-1.48)\end{array}$ \\
\hline Acute-phase reactants & CRP, mg/dl (0.1-10.0) & - & $\begin{array}{c}\text { ESR, log transformed } \\
(0.23-1.51)^{* *}\end{array}$ & $\begin{array}{l}\text { ESR, log transformed } \\
\quad(0.49-3.22)^{* *}\end{array}$ \\
\hline Patient global disease activity & VAS, cm (0-10.0) & VAS, cm (0-10.0) & - & - \\
\hline Evaluator global disease activity & VAS, cm (0-10.0) & VAS, cm (0-10.0) & - & - \\
\hline Total index & $\begin{array}{c}\text { No immediate scoring } \\
\text { due to CRP; simple } \\
\text { calculation possible } \\
(0.1-86.0)\end{array}$ & $\begin{array}{l}\text { Immediate scoring due } \\
\text { to CRP; simple } \\
\text { calculation possible } \\
(0.1-76.0)\end{array}$ & $\begin{array}{c}\text { No immediate scoring } \\
\text { due to ESR; simple } \\
\text { calculator required } \\
(0.23-9.87)\end{array}$ & $\begin{array}{c}\text { No immediate scoring } \\
\text { due to ESR; simple } \\
\text { calculator required } \\
(0.49-9.07)\end{array}$ \\
\hline
\end{tabular}

\footnotetext{
* Based on transformation and weighting of individual elements according to the formula of the respective index; assumed ranges are 2-100 mm/h for ESR, and $0.1-10 \mathrm{mg} / \mathrm{dl}$ for CRP. Table reproduced with permission (Clin Exp Rheumatol 2005;23 Suppl 39:S100-8). ** The DAS and DAS28 formulae have also been modified to include CRP instead of ESR, and to substitute the patient global health by a constant. These versions are less commonly used and not well validated. CRP: C-reactive protein; ESR: erythrocyte sedimentation rate; VAS: visual analog scale.
} Personal non-commercial use only. The Journal of Rheumatology Copyright @ C 2010. All rights reserved. 
Table 2. Cutoff levels for disease activity states ${ }^{36}$.

\begin{tabular}{lcccc}
\hline & \multicolumn{3}{c}{ Disease Activity State } \\
Scale & Low & Moderate & High & Remission \\
\hline CDAI & $\leq 10$ & $>10$ and $\leq 22$ & $>22$ & $<2.8$ \\
SDAI & $\leq 11$ & $>11$ and $\leq 26$ & $>26$ & $<3.3$ \\
DAS28 & $\leq 3.2$ & $>3.2$ and $\leq 5.1$ & $>5.1$ & $<2.6$ \\
\hline
\end{tabular}

CDAI: Clinical Disease Activity Index; DAS28: 28-joint Disease Activity Score; SDAI: Simplified Disease Activity Index.

\section{Visual analog scale}

No pain

$10 \mathrm{~cm}$

\section{MDHAQ (RAPID-3) questionnaire}

\section{RAPID3 Multidimensional Health Assessment Questionnaire (MDHAQ)}

YOUR NAME: Date of Birth: Today's date:

1. Please check (8) the ONE best answer for your abilities at this time:

\begin{tabular}{|c|c|c|c|c|}
\hline OVER THE PAST WEEK, were you able to: & $\begin{array}{l}\text { Waheut } \\
\text { ANY } \\
\text { difficuty }\end{array}$ & $\begin{array}{l}\text { With } \\
\text { SOME } \\
\text { difficulty }\end{array}$ & $\begin{array}{l}\text { Weth } \\
\text { MUCH } \\
\text { difficuty }\end{array}$ & $\begin{array}{c}\text { UNABLE } \\
\text { to do }\end{array}$ \\
\hline Dress yourseit, including tying shodlaces, doing butlons? & $\square 0$ & $\square 1$ & $\square 2$ & $\square 3$ \\
\hline Get in and out of bed? & 0 & $\square 1$ & $\square 2$ & $\square 3$ \\
\hline Lift a ful cup or glass to your mouth? & 0 & $\square 1$ & $\square 2$ & $\square 3$ \\
\hline Wak outdocrs on flat ground? & 0 & $\square 1$ & $\square 2$ & $\square 3$ \\
\hline Wash and dry your entire booy? & $\square 0$ & $\square 1$ & $\square 2$ & $\square 3$ \\
\hline Bend down and pick up clathing from the floor? & $\square 0$ & $\square 1$ & $\square 2$ & $\square 3$ \\
\hline Tum regular taucess on and off? & $\square 0$ & $\square 1$ & $\square 2$ & $\square 3$ \\
\hline Get in and out of a car, bus, train, or airplane? & $\square 0$ & $\square 1$ & $\square 2$ & $\square 3$ \\
\hline Walk two miles? & $\square 0$ & $\square 1$ & $\square 2$ & $\square 3$ \\
\hline Participste in sports and games as you would lke? & $\square 0$ & $\square 1$ & $\square_{2}$ & $\square 3$ \\
\hline
\end{tabular}

2. How much pain have you had because of your condition OVER THE PAST WEEK? Please indicate below how severe your pain has been:
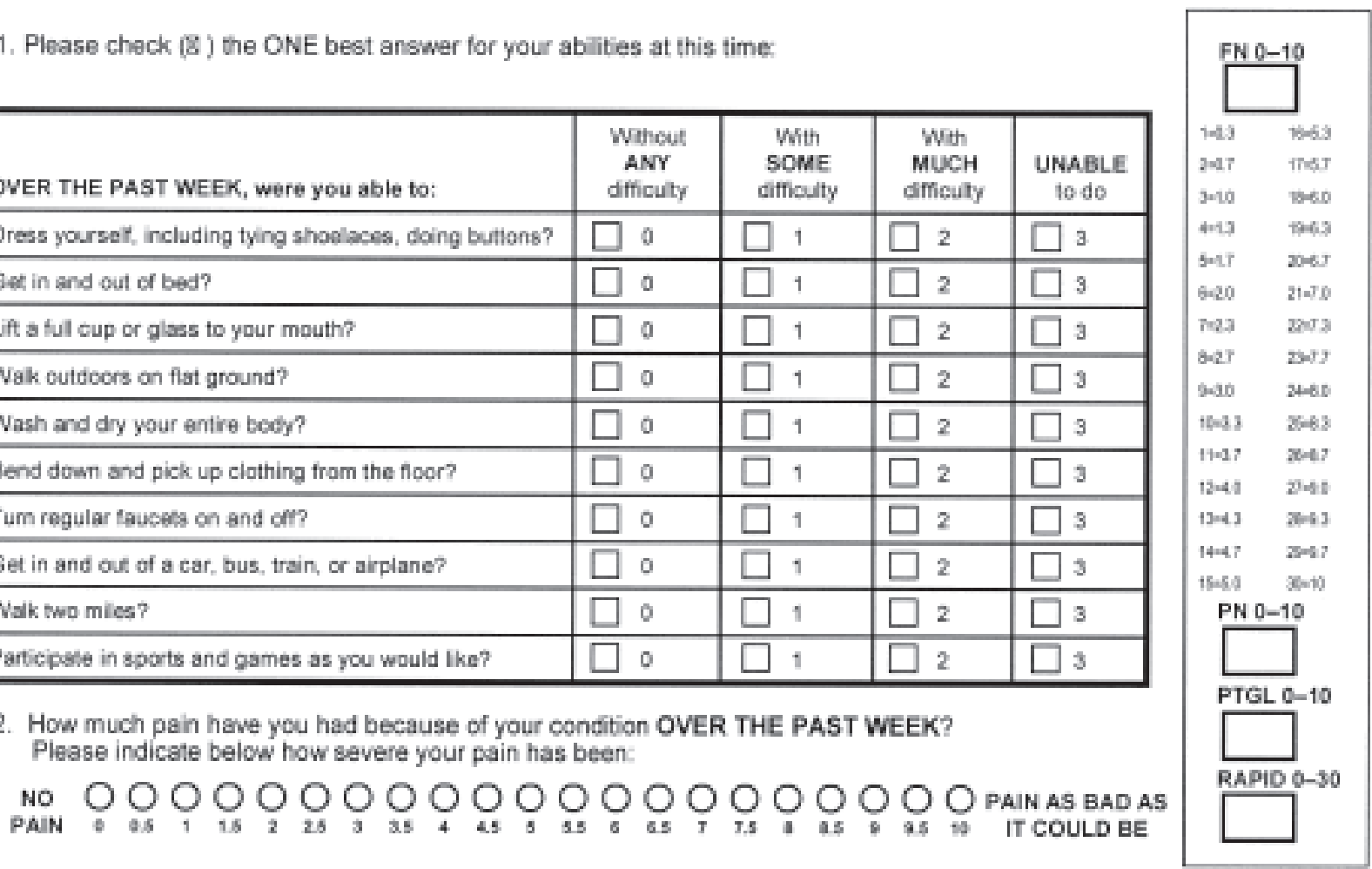

3. Considering all the ways in which illness and health conditions may affect you at this time, please indicate below how you are doing:

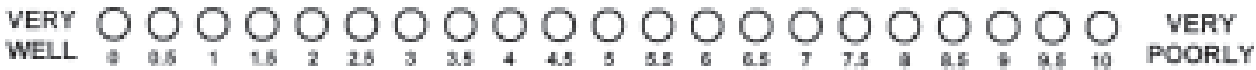

Figure 1. Comparison of visual scales used to assess pain. MDHAQ: Multidimensional Health Assessment Questionnaire. From Best Pract Res Clin Rheumatol 2007;21:755-87, with permission. 
1). The form takes substantially less time for the physician to assess and score compared with the HAQ. If more rapid assessment is required, physical function, pain, and global status scores can be registered at a glance and formally scored in about 10 seconds into a composite index known as the Rheumatology Assessment Patient Index Data (RAPID)- ${ }^{41}$. RAPID-3 can be expanded by adding the Rheumatoid Arthritis Disease Activity Index self-report (RAPID-4) and the physician/assessor global estimate (RAPID-5) templates that are included in the MDHAQ forms. These forms and instructions for their use can be downloaded from www.mdhaq.org.

\section{Do We Have the Tools to Achieve Tight RA Control in Routine Clinical Practice?}

As treatment for RA improves, remission becomes an important and more achievable goal, and so it is essential that clinicians are able to accurately measure low levels of disease activity. Validated tools are now available for evaluating a range of clinical variables in patients with RA, but definitions of remission are not always standardized. Several different definitions of remission are currently used, and so variation in remission rates between clinical trials may be due to the indices used, rather than the treatments received. Indeed, a recent study in which patients' disease activity was assessed by different indices (including DAS28, SDAI, and CDAI) demonstrated that different proportions of patients were found to be in remission depending on the definition used ${ }^{42}$; further comparisons of disease activity indices are therefore required. A collaborative committee between ACR and EULAR has been convened to develop a strict definition of remission that correlates with very low or no disease activity 22 .

The case study below illustrates that routine disease assessment, using a simplified tool such as the CDAI, could provide valuable guidance when selecting initial therapy, and an indication of when treatment intensification or a switch in medication is required.

\section{Case Study}

A 42-year-old woman presented with a 12-month history of RA. Her primary care physician prescribed ibuprofen and prednisone, and referred her to a consultant rheumatologist. Her first rheumatologist initiated MTX 3 months after diagnosis and her symptoms initially improved before worsening. She decided to transfer her care as the rheumatologist was reluctant to initiate biologic therapy.

At presentation, her symptoms included morning stiffness (lasting 1 hour), polyarticular pain, fatigue, and difficulty with her work as a receptionist. The medication on presentation included MTX $20 \mathrm{mg} /$ week, folic acid 1 $\mathrm{mg}$ /day, prednisone $5 \mathrm{mg}$ /day, and ibuprofen $800 \mathrm{mg} 3$ times daily. Her baseline characteristics are shown in Table 3 . Hand radiographs showed erosions at both second metacar- pophalangeal (MCP) joints. With a CDAI of 23 , she was considered to have high disease activity ${ }^{24}$ (Tables 2 and 3), while her SDAI and DAS28 indicated moderate disease activity (Tables 2 and 3). She was considered a suitable candidate for TNF inhibitor therapy and agreed to this course of treatment.

Following a negative tuberculosis skin test, etanercept 50 $\mathrm{mg} /$ week was initiated. The tight control model of optimal care was agreed upon, and treatment was temporarily increased to MTX $25 \mathrm{mg} /$ week and prednisone $10 \mathrm{mg} /$ day, while awaiting the full effect of etanercept therapy. CDAI was the principal assessment tool, with a treatment goal of low disease activity; SDAI and DAS28 were calculated when CRP levels were available.

Disease control during Years 1 and 2 are summarized in Table 3. After 1 month, the patient had low to moderate disease activity and the treatment regimen was continued. After 2 months, she was considered to have low disease activity and MTX was reduced to $20 \mathrm{mg} /$ week and prednisone to 5 $\mathrm{mg} /$ day. After 3 months, disease activity scores were unchanged and the treatment regimen was maintained at this level. She continued to exhibit low disease activity over the following 2 years and prednisone was discontinued altogether after 6 months.

Treatment modification on loss of disease control. Two years after starting etanercept, she began to experience increased RA symptoms (Table 3) and fatigue. She had elevated liver function tests and radiographic evidence of one new erosion in her third left MCP joint. Prednisone was temporarily reintroduced at $20 \mathrm{mg} / \mathrm{day}$, and tapered over 1 month. MTX was not increased because of the liver test abnormalities. At the 1-month followup visit, disease activity remained high, despite the higher prednisone dose.

Considering the next course of action, the results of the study by Finckh and coworkers ${ }^{44}$ were taken into account. That study suggests that on failure of a TNF inhibitor, switching to an agent with a different mechanism of action, such as $\mathrm{B}$ cell depletion, may be more effective in regaining disease control than an alternative TNF inhibitor. Therefore, rituximab was initiated ( 2 times $1000 \mathrm{mg}$ infusions separated by 2 weeks), along with prednisone $10 \mathrm{mg} /$ day and MTX 12.5 $\mathrm{mg} /$ week. One month later, the patient had low to moderate disease activity (Table 3) and at the 3-month followup visit, her CDAI was 8 , indicating low disease activity. Liver tests had normalized and prednisone was decreased to $5 \mathrm{mg} /$ day.

She continues to be seen in the clinic every 2 months. Her CDAI score remains low, suggesting good disease control, and her overall global and functional status remains good. Repeat hand radiographs 1 year after initiation of rituximab showed no new erosions. Based on recent data suggesting optimal disease control with fixed retreatment schedules and several trials suggesting 6-month intervals $45,46,47,48,49$, she is receiving repeat courses of rituximab at this interval. Personal non-commercial use only. The Journal of Rheumatology Copyright @ 2010 . All rights reserved. 
Table 3. Disease control over time in the patient described in the case study.

\begin{tabular}{|c|c|c|c|c|c|c|}
\hline \multirow[t]{2}{*}{ Outcome } & \multirow[t]{2}{*}{ Baseline } & \multicolumn{3}{|c|}{ Etanercept } & \multicolumn{2}{|c|}{ Rituximab } \\
\hline & & Month 1 & Month 2 & Year 2 & Month 1 & Month 2 \\
\hline \multicolumn{7}{|l|}{ Joints } \\
\hline Swollen & 4 & - & 0 & 6 & 2 & 1 \\
\hline Tender & 7 & - & 2 & 10 & 3 & 2 \\
\hline \multicolumn{7}{|c|}{ Global assessment } \\
\hline Patient & 6 & 4 & 2 & 6 & 4 & 3 \\
\hline Physician & 5 & 3 & 1 & 5 & 3 & 2 \\
\hline CDAI & 23 & 13 & 5 & 27 & 12 & 8 \\
\hline \multicolumn{7}{|c|}{ Laboratory values } \\
\hline $\mathrm{CRP}, \mathrm{mg} / \mathrm{dl}$ & 1.5 & 0.8 & 0.6 & 1.2 & - & 0.8 \\
\hline $\mathrm{RF}$, units & 128 & & & & & \\
\hline $\mathrm{CCP}$, units & 85 & & & & & \\
\hline SDAI & 24.5 & 13.8 & 5.6 & 28.5 & - & 8.8 \\
\hline DAS28 & 4.94 & 3.77 & 2.73 & 5.18 & - & 3.24 \\
\hline
\end{tabular}

CDAI: Clinical Disease Activity Index; CRP: C-reactive protein; DAS28: 28-joint Disease Activity Score; RF: rheumatoid factor; SDAI: Simplified Disease Activity Index; CCP: citric citrullinated peptide antibody.

For this patient, TNF inhibition was initiated with the aim of achieving tight disease control. Low disease activity, measured using the CDAI, SDAI, and DAS28, was the clinical target. An increase in disease activity prompted reevaluation of treatment and a switch to an alternative biologic agent to regain tight disease control.

\section{Conclusions}

The concept of tight control - intensive disease management based on specific clinical variables - is well accepted in the management of many chronic conditions and has improved patient outcomes. In patients with RA, there is currently no gold standard for assessing disease activity and outcomes, so patients may not receive optimal treatment over time. Studies have shown that tight control and intensive treatment can significantly improve outcomes compared with standard approaches in RA, regardless of the treatment received. It remains to be seen whether tight control can not only control disease activity and reduce radiographic progression, but also reduce the increased risk of early cardiovascular morbidity and mortality due to inflammation-induced atherogenesis, an important comorbidity of RA. Nonetheless, the weight of evidence from well designed controlled clinical trials indicates that the principles of tight disease control should now be applied by all physicians in routine clinical practice. The overriding principle of the tight control approach is not the choice of individual therapies but rather the regular monitoring of patients and early switching or adjustment of therapies that fail to adequately control disease activity. On a practical note, the implementation of tight control into routine care will require quick and simple validated tools for defining treatment targets and monitoring disease activity. Tools such as the CDAI and RAPID-3 appear to meet these requirements; in addition, the CDAI appears not only to provide simplicity but also, as recent studies suggest ${ }^{38,39}$, to be a more stringent tool for assessing remission. However, further studies are still needed to define the most appropriate assessment tools for assessing remission in routine clinical practice, as well as appropriate and achievable clinical targets reflecting tight disease control. Ultimately, the use of tight control should lead to treatment optimization and will provide the best chances of improvement and remission for patients with RA.

\section{REFERENCES}

1. Kvien TK. Epidemiology and burden of illness of rheumatoid arthritis. Pharmacoeconomics 2004;22 Suppl 2:1-12.

2. Gabriel SE, Crowson CS, O'Fallon WM. Mortality in rheumatoid arthritis: have we made an impact in 4 decades? J Rheumatol 1999;26:2529-33.

3. Crowson CS, Myasoedova E, Matteson EL, Maradit-Kremers H, Therneau TM, Gabriel SE. Has survival improved in patients recently diagnosed with rheumatoid arthritis? [abstract]. Arthritis Rheum 2009;60 Suppl:S436.

4. Pincus T, Yazici Y, Sokka T. Quantitative measures of rheumatic diseases for clinical research versus standard clinical care: differences, advantages and limitations. Best Pract Res Clin Rheumatol 2007;21:601-28.

5. Havas S, Donner T. Tight control of type 1 diabetes: recommendations for patients. Am Fam Physician 2006;74:971-8.

6. Diabetes Control and Complications Trial (DCCT) Research Group. Effect of intensive diabetes management on macrovascular events and risk factors in the Diabetes Control and Complications Trial. Am J Cardiol 1995;75:894-903.

7. Egan BM, Lackland DT, Cutler NE. Awareness, knowledge, and attitudes of older Americans about high blood pressure: implications for health care policy, education, and research. Arch Intern Med 2003;163:681-7.

8. Rachmani R, Slavacheski I, Berla M, Frommer-Shapira R, Ravid $\mathrm{M}$. Treatment of high-risk patients with diabetes: motivation and teaching intervention: a randomized, prospective 8-year follow-up study. J Am Soc Nephrol 2005;16 Suppl 1:S22-6.

9. Mottonen T, Hannonen P, Leirisalo-Repo M, Nissila M, Kautiainen $\mathrm{H}$, Korpela M, et al. Comparison of combination therapy with 
single-drug therapy in early rheumatoid arthritis: a randomised trial. FIN-RACo Trial Group. Lancet 1999;353:1568-73.

10. Arnett FC, Edworthy SM, Bloch DA, McShane DJ, Fries JF, Cooper NS, et al. The American Rheumatism Association 1987 revised criteria for the classification of rheumatoid arthritis. Arthritis Rheum 1988;31:315-24.

11. Pinals RS, Masi AT, Larsen RA. Preliminary criteria for clinical remission in rheumatoid arthritis. Arthritis Rheum 1981;24:1308-15.

12. Korpela M, Laasonen L, Hannonen P, Kautiainen H, Leirisalo-Repo M, Hakala M, et al. Retardation of joint damage in patients with early rheumatoid arthritis by initial aggressive treatment with disease-modifying antirheumatic drugs: five-year experience from the FIN-RACo study. Arthritis Rheum 2004;50:2072-81.

13. Goekoop-Ruiterman YP, Vries-Bouwstra JK, Allaart CF, van Zeben D, Kerstens PJ, Hazes JM, et al. Clinical and radiographic outcomes of four different treatment strategies in patients with early rheumatoid arthritis (the BeSt study): a randomized, controlled trial. Arthritis Rheum 2005;52:3381-90.

14. Goekoop-Ruiterman YP, de Vries-Bouwstra JK, van Zeben D, Kerstens PJ, Hazes JM, Zwinderman AE. Clinical and radiological efficacy of different treatment strategies: 2 year follow-up of the BeSt study [abstract]. Ann Rheum Dis 2005;64 Suppl III:58.

15. Goekoop-Ruiterman YP, Vries-Bouwstra JK, Allaart CF, van Zeben D, Kerstens PJ, Hazes JM, et al. Comparison of treatment strategies in early rheumatoid arthritis: a randomized trial. Ann Intern Med 2007;146:406-15

16. Goekoop-Ruiterman YP, Vries-Bouwstra JK, Kerstens PJ, Nielen MM, Vos K, van Schaardenburg D, et al. DAS-driven therapy versus routine care in patients with recent-onset active rheumatoid arthritis. Ann Rheum Dis 2010;69:65-9.

17. Grigor C, Capell H, Stirling A, McMahon AD, Lock P, Vallance R, et al. Effect of a treatment strategy of tight control for rheumatoid arthritis (the TICORA study): a single-blind randomised controlled trial. Lancet 2004;364:263-9.

18. Verstappen SM, Jacobs JW, van der Veen MJ, Heurkens AH, Schenk Y, ter Borg EJ, et al. Intensive treatment with methotrexate in early rheumatoid arthritis: aiming for remission. Computer Assisted Management in Early Rheumatoid Arthritis (CAMERA, an open-label strategy trial). Ann Rheum Dis 2007;66:1443-9.

19. van Tuyl LH, Lems WF, Voskuyl AE, Kerstens PJ, Garnero P, Dijkmans BA, et al. Tight control and intensified COBRA combination treatment in early rheumatoid arthritis: 90\% remission in a pilot trial. Ann Rheum Dis 2008;67:1574-7.

20. Tanaka E, Mannalithara A, Inoue E, Hara M, Tomatsu T, Kamatani $\mathrm{N}$, et al. Efficient management of rheumatoid arthritis significantly reduces long-term functional disability. Ann Rheum Dis 2008;67:1153-8.

21. Sano H, Arai K, Murai T, Fujisawa J, Kondo N, Netsu T, et al Tight control is important in patients with rheumatoid arthritis treated with an anti-tumor necrosis factor biological agent: prospective study of 91 cases who used a biological agent for more than 1 year. Mod Rheumatol 2009;19:390-4.

22. van Tuyl LH, Vlad SC, Felson DT, Wells G, Boers M. Defining remission in rheumatoid arthritis: results of an initial American College of Rheumatology/European League Against Rheumatism consensus conference. Arthritis Rheum 2009;61:704-10.

23. Prevoo ML, van 't Hof MA, Kuper HH, van Leeuwen MA, van de Putte LB, van Riel PL. Modified disease activity scores that include twenty-eight-joint counts. Development and validation in a prospective longitudinal study of patients with rheumatoid arthritis. Arthritis Rheum 1995;38:44-8.

24. Aletaha D, Smolen J. The Simplified Disease Activity Index (SDAI) and the Clinical Disease Activity Index (CDAI): a review of their usefulness and validity in rheumatoid arthritis. Clin Exp Rheumatol 2005;23 Suppl 39:S100-8.
25. Felson DT, Anderson JJ, Boers M, Bombardier C, Chernoff M, Fried B, et al. The American College of Rheumatology preliminary core set of disease activity measures for rheumatoid arthritis clinical trials. The Committee on Outcome Measures in Rheumatoid Arthritis Clinical Trials. Arthritis Rheum 1993; 36:729-40.

26. Fransen J, Langenegger T, Michel BA, Stucki G. Feasibility and validity of the RADAI, a self-administered rheumatoid arthritis disease activity index. Rheumatology 2000;39:321-7.

27. Pincus T. The American College of Rheumatology (ACR) core data set and derivative "patient only" indices to assess rheumatoid arthritis. Clin Exp Rheumatol 2005;23 Suppl 39:S109-13.

28. Fransen J, van Riel PL. The Disease Activity Score and the EULAR response criteria. Clin Exp Rheumatol 2005;23 Suppl 39:S93-9.

29. Goldsmith CH, Boers M, Bombardier C, Tugwell P. Criteria for clinically important changes in outcomes: development, scoring and evaluation of rheumatoid arthritis patient and trial profiles. OMERACT Committee. J Rheumatol 1993;20:561-5.

30. van der Heijde DM, van 't Hof M, van Riel PL, van de Putte LB. Development of a disease activity score based on judgment in clinical practice by rheumatologists. J Rheumatol 1993;20:579-81.

31. van Riel PL. Provisional guidelines for measuring disease activity in clinical trials on rheumatoid arthritis. Br J Rheumatol 1992;31:793-4.

32. van der Heijde DM, van 't Hof MA, van Riel PL, Theunisse LA, Lubberts EW, van Leeuwen MA, et al. Judging disease activity in clinical practice in rheumatoid arthritis: first step in the development of a disease activity score. Ann Rheum Dis 1990;49:916-20.

33. DAS. How to use the DAS28. Updated 2004. [Internet. Accessed April 15, 2010.] Available from: http://www.das-score.nl/www. das-score.nl/how_to_use $1 . h t m l$

34. van Gestel AM, Prevoo ML, van 't Hof MA, van Rijswijk MH, van de Putte LB, van Riel PL. Development and validation of the European League Against Rheumatism response criteria for rheumatoid arthritis. Comparison with the preliminary American College of Rheumatology and the World Health Organization/International League Against Rheumatism Criteria. Arthritis Rheum 1996;39:34-40.

35. Prevoo ML, van Gestel AM, van 't Hof MA, van Rijswijk MH, van de Putte LB, van Riel PL. Remission in a prospective study of patients with rheumatoid arthritis. American Rheumatism Association preliminary remission criteria in relation to the Disease Activity Score. Br J Rheumatol 1996;35:1101-5.

36. Saag KG, Teng GG, Patkar NM, Anuntiyo J, Finney C, Curtis JR, et al. American College of Rheumatology 2008 recommendations for the use of nonbiologic and biologic disease-modifying antirheumatic drugs in rheumatoid arthritis. Arthritis Rheum 2008;59:762-84.

37. Smolen JS, Breedveld FC, Schiff MH, Kalden JR, Emery P, Eberl $\mathrm{G}$, et al. A simplified disease activity index for rheumatoid arthritis for use in clinical practice. Rheumatology 2003;42:244-57.

38. Rintelen B, Sautner J, Haindl P, Andel I, Maktari A, Leeb B. Comparison of three rheumatoid arthritis disease activity scores in clinical routine. Scand J Rheumatol 2009;7:1-7.

39. Smolen JS, Alasti F, Aletaha D. The measure of disease activity, but not reduction of the acute phase response (APR), determines attainment of disease activity states by tocilizumab [abstract]. Arthritis Rheum 2009;60 Suppl:S601.

40. Fries JF, Spitz P, Kraines RG, Holman HR. Measurement of patient outcome in arthritis. Arthritis Rheum 1980;23:137-45.

41. Pincus T, Yazici Y, Bergman M. A practical guide to scoring a Multi-Dimensional Health Assessment Questionnaire (MDHAQ) and Routine Assessment of Patient Index Data (RAPID) scores in 10-20 seconds for use in standard clinical care, without rulers, 
calculators, websites or computers. Best Pract Res Clin Rheumatol 2007;21:755-87.

42. Khanna D, Oh M, Furst DE, Ranganath V, Gold RH, Sharp JT, et al. Evaluation of the preliminary definitions of minimal disease activity and remission in an early seropositive rheumatoid arthritis cohort. Arthritis Rheum 2007;57:440-7.

43. Zatarain E, Strand V. Monitoring disease activity of rheumatoid arthritis in clinical practice: contributions from clinical trials. Nat Clin Pract Rheumatol 2006;2:611-8.

44. Finckh A, Ciurea A, Brulhart L, Kyburz D, Moller B, Dehler S, et al. B cell depletion may be more effective than switching to an alternative anti-tumor necrosis factor agent in rheumatoid arthritis patients with inadequate response to anti-tumor necrosis factor agents. Arthritis Rheum 2007;56:1417-23.

45. Emery P, Rigby WF, Combe B, Latinis K, Szczepanski L, Roschmann RA, et al. Efficacy and safety of rituximab as first-line biologic therapy in patients with active rheumatoid arthritis: Results of a phase III randomized controlled study (SERENE) [abstract]. Arthritis Rheum 2008;58 Suppl:S302.
46. Mease P, Keystone E, Kaell A, Emery P, St. Clair EW, Dougados M, et al. Recent disease activity affects outcome of second course of rituximab for RA [abstract]. Arthritis Rheum 2006;54 Suppl:S236.

47. Mease P, Keystone E, Kaell A, Emery P, St. Clair EW, Dougados $\mathrm{M}$, et al. Predicting outcome of a second course of rituximab for rheumatoid arthritis [abstract]. Ann Rheum Dis 2007;66 Suppl II:434.

48. Mease PJ, Cohen S, Gaylis NB, Chubick A, Kaell AT, Greenwald $\mathrm{M}$, et al. Efficacy, safety and dose frequency of retreatment with rituximab in RA: Results from a randomized controlled trial (SUNRISE) [abstract]. Arthritis Rheum 2008;58 Suppl:S619.

49. Mease PJ, Keystone E, Kaell A, Emery P, St. Clair EW, Dougados $\mathrm{M}$, et al. SDAI and CDAI for predicting outcome of a second course of rituximab for patients with rheumatoid arthritis [abstract]. Ann Rheum Dis 2008;67 Suppl II:196. 